\title{
High incidence of hypoglycemia from an audit of glycemic control and management in patients with diabetes in a cardiac unit
}

\author{
May Lea Ong ${ }^{1}{ }^{*}$, Helena J. Teede ${ }^{1,2,3}$, Sophia Zoungas ${ }^{1,2,3}$ and Jennifer L. A. Wong ${ }^{1,2,3}$ \\ ${ }^{1}$ Monash Health, Clayton, VIC, Australia \\ ${ }^{2}$ Monash University, Clayton, VIC, Australia \\ ${ }^{3}$ School of Public Health and Preventive Medicine, Clayton, VIC, Australia \\ *Correspondence: jacqui.ong@gmail.com
}

Edited by:

Ake Sjoholm, Karolinska Institutet, Sweden

Keywords: diabetes, hypoglycemia, glycemia, cardiac, coronary care

\section{INTRODUCTION}

The coronary care unit (CCU) model of care has evolved considerably over the past several decades and emerged as one of the most important advances in the care of patients with acute coronary syndrome (ACS). The concept of a specific unit for patients with ACS equipped with highly trained and specialized staff was initially introduced in the 1960s, but it was not until 1980s that the idea took off with the advent of coronary angiography and fibrinolytic therapy (1). However, in this new modern environment with high rate of cardiac interventions and patient turnover, many challenges have been created with competing demands for nursing time. These challenges are even greater in patients with diabetes frequently who require rapid intensification of therapy to optimize blood glucose levels whilst needing procedures which require fasting.

The prevalence of diabetes in hospitalized patients is significant and is on an increasing trend. However, this figure is not well documented and hence significantly underestimated $(2,3)$. More than a decade ago, $12.4 \%$ of hospital discharges in the United States have diabetes documented as a diagnosis (4). More recently, the prevalence of diabetes was recorded from at least $10 \%$ and up to $25 \%$ of adult patients admitted to hospitals in the United Kingdom (5). Not surprisingly, this figure is increased in high-risk groups, particularly, patients admitted to a CCU. A 11years review of patients admitted to a CCU in Italy found a prevalence of diabetes at $31.5 \%$ and almost $40 \%$ with concomitant ST-elevation myocardial infarction (6).
The combination of the busy modern CCU environment and the high and increasing number of patients with diabetes creates a high-risk setting for hypoglycemia. Severe hypoglycemia is known to be associated with increased morbidity and mortality in hospitalized patients and has been postulated to be associated to a range of adverse clinical outcomes or at least a marker of vulnerability to such events (7). This finding has been extended to patients hospitalized with ACS, where severe hypoglycemia was a major predictor of cardiovascular death (8). Similarly, hypoglycemia has also been implicated in the excess allcause mortality observed in this patient group (9).

\section{METHODS AND RESULTS}

In the setting of the overwhelming concern about the negative association between hypoglycemia and adverse cardiovascular events, we undertook a prospective audit of glycemic control and management of 46 patients with diabetes in the cardiac unit of one of the largest tertiary health center in Australia, Monash Health $(\mathrm{MH})$ during May and June 2012. The characteristics of the patients, length of stay and the principle diagnosis on admission are presented on the Table 1.

On admission the majority of the patients were treated with oral glucose lowering agents alone $(61 \%)$ and these agents were continued during hospitalization in $43 \%$ of patient, with only $46 \%$ of patients receiving additional supplemental insulin. The majority of blood glucose measurements were normoglycemic (58\%). In $33 \%$ of patients, at least one hypoglycemic episode was recorded, with the majority having a recurrence (73\%). However, most hypoglycemic episodes were mild (80\%).

\section{CONCLUSION}

In light of these findings, barriers to the prevention of hypoglycemia were explored with staff, which included competing demands on nurses resulting in variable administration times for glucose lowering medications and fasting for procedures with repeated rescheduling. Identifying those at risk and intervening before and after hypoglycemia occurs were clearly important given the high rates of recurrence.

These findings created an impetus for strategies to prevent hypoglycemia especially in the modern CCU environment. In the case of $\mathrm{MH}$, strategies implemented after the audit included in-service training highlighting the need to prioritize those with diabetes on procedural lists, engagement of a diabetes nurse educators to support CCU nursing staff and implementation of hospital policies concerning prevention and management of hypoglycemia in fasting patients with diabetes. The MH policy for pre-procedural medication management in fasting patients with diabetes was also established and involved omitting morning dose of oral hypoglycemics, short-acting, and pre-mixed insulin on the day of the procedure when fasting from midnight. However, if fasting from breakfast, oral hypoglycemics will still need to be omitted, whereas if on insulin, only 80 and $50 \%$ of the usual dose should be administered 
Table 1 | Baseline characteristics of patients, length of stay, principal diagnoses, glycemic management and control.

\begin{tabular}{|c|c|}
\hline \multicolumn{2}{|l|}{ Patient characteristic } \\
\hline Mean age $\pm S D$ years & $69 \pm 10$ \\
\hline Male, $n(\%)$ & $37(80)$ \\
\hline Female, $n(\%)$ & $9(20)$ \\
\hline Duration of diabetes $\pm S D$ years & $12 \pm 10$ \\
\hline Mean $\mathrm{HbA} 1 \mathrm{c}$ on admission $\pm \mathrm{SD}$ & $7.3 \pm 1.5$ \\
\hline Length of stay $\pm S D$ days & $8 \pm 5$ \\
\hline \multicolumn{2}{|l|}{ Principal diagnoses, $\boldsymbol{n}(\%)$} \\
\hline Acute coronary syndrome & $25(54)$ \\
\hline Cardiac failure & $10(22)$ \\
\hline Arrhythmia & $3(7)$ \\
\hline Conduction defect & $3(7)$ \\
\hline Chest pain for investigation & $2(4)$ \\
\hline Valvular condition & $2(4)$ \\
\hline \multicolumn{2}{|l|}{ Outpatient diabetes management, $\boldsymbol{n}(\%)$} \\
\hline $\mathrm{OHA}$ & $28(61)$ \\
\hline Insulin & $6(13)$ \\
\hline $\mathrm{OHA}$ and insulin & $7(15)$ \\
\hline \multicolumn{2}{|l|}{ Inpatient diabetes management, $\boldsymbol{n}(\%)$} \\
\hline Same as outpatient & $20(43)$ \\
\hline Additional supplemental insulin & $21(46)$ \\
\hline Additional pre-mixed insulin & $3(7)$ \\
\hline Additional basal insulin & $2(4)$ \\
\hline Insulin infusion & $1(2)$ \\
\hline \multicolumn{2}{|l|}{ Inpatient glycemic control } \\
\hline Normoglycemic readings (4-10 mmol/l), $n(\%)$ & $985(58)$ \\
\hline Hyperglycemia readings (>10.1 mmol/l), $n(\%)$ & $554(33)$ \\
\hline Mild hypoglycemia readings ( $\geq 2.8-3.9 \mathrm{mmol} / \mathrm{l}), n(\%)$ & $40(2)$ \\
\hline Severe hypoglycemia reading $(<2.8 \mathrm{mmol} / \mathrm{l}) n(\%)$ & $8(20)$ \\
\hline Hypoglycemic patients, $n(\%)$ & $15(33)$ \\
\hline Recurrence, $n(\%)$ & $11(73)$ \\
\hline Severe, $n(\%)$ & $5(33)$ \\
\hline
\end{tabular}

SD, standard deviation.

if on short-acting and pre-mixed insulin respectively.

\section{KEY MESSAGES}

- Coronary care unit creates a high-risk setting for hypoglycemia which is known to be associated with increased mortality and morbidity

- Patients with an initial episode of hypoglycemia are likely to have a recurrence
- Proactive strategies need to be in place to reduce the risk of hypoglycemia

\section{ACKNOWLEDGMENTS}

This research received no specific grant from any funding agency in the public, commercial, or not-for-profit sectors.

\section{REFERENCES}

1. Desmond J. Review: landmark development in clinical cardiology over the last 50 years. $\mathrm{Br} J$
Diabetes Vasc Dis (2002) 2(6):429-33. doi:10.1177/ 14746514020020060301

2. Jencks SF. Accuracy in recorded diagnoses. JAMA (1992) 267:2238-9. doi:10.1001/jama.267. 16.2238

3. Levetan CS, Passaro M, Jablonski K, Kass M, Ratner RE. Unrecognized diabetes among hospitalized patients. Diabetes Care (1998) 21:246-9. doi:10. 2337/diacare.21.2.246

4. Tierney E. Data from the National Hospital Discharge Survey Database 2000, Center of Disease Control and Prevention, Division of Diabetes Translation. Atlanta, GA: U.S. Department of Health and Human Services, Centers for Disease Control and Prevention, National Centre for Health Statistics (2003) Personal communication.

5. Sampson MJ, Brennan C, Dhatariya K, Jones C, Walden E. A national survey of in-patient diabetes services in the United Kingdom. Diabet Med (2007) 24:643-9. doi:10.1111/j.1464-5491.2007.02156.x

6. Novo G, Scordato F, Cerruto G, Vitale G, Ciaramitaro G, Coppola G, et al. In-hospital stay of patient with acute coronary syndrome with or without diabetes mellitus. Minerva Cardioangiol (2009) 57(2):159-64.

7. Zoungas S, Patel A, Chalmers J, de Galan BE, Li $\mathrm{Q}$, Billot $\mathrm{L}$, et al. Severe hypoglycemia and risks of vascular events and death. N Engl J Med (2010) 363:1410-8. doi:10.1056/NEJMoa1003795

8. Frier BM, Schernthaner G, Heller SR. Hypoglycemia and cardiovascular risks. Diabetes Care (2011) 34(2):132-7. doi:10.2337/dc11-s220

9. Svensson AM, McGuire DK, Abrahamsson P, Dellborg M. Association between hyper- and hypoglycaemia and 2 year all-cause mortality risk in diabetic patients with acute coronary events. Eur Heart J (2005) 26(13):1255-61. doi:10.1093/eurheartj/ ehi230

Received: 14 October 2013; accepted: 23 October 2013; published online: 07 November 2013.

Citation: Ong ML, Teede HJ, Zoungas S and Wong JLA (2013) High incidence of hypoglycemia from an audit of glycemic control and management in patients with diabetes in a cardiac unit. Front. Endocrinol. 4:168. doi: 10.3389/fendo.2013.00168

This article was submitted to Diabetes, a section of the journal Frontiers in Endocrinology.

Copyright $\odot 2013$ Ong, Teede, Zoungas and Wong. This is an open-access article distributed under the terms of the Creative Commons Attribution License (CC BY). The use, distribution or reproduction in other forums is permitted, provided the original author(s) or licensor are credited and that the original publication in this journal is cited, in accordance with accepted academic practice. No use, distribution or reproduction is permitted which does not comply with these terms. 